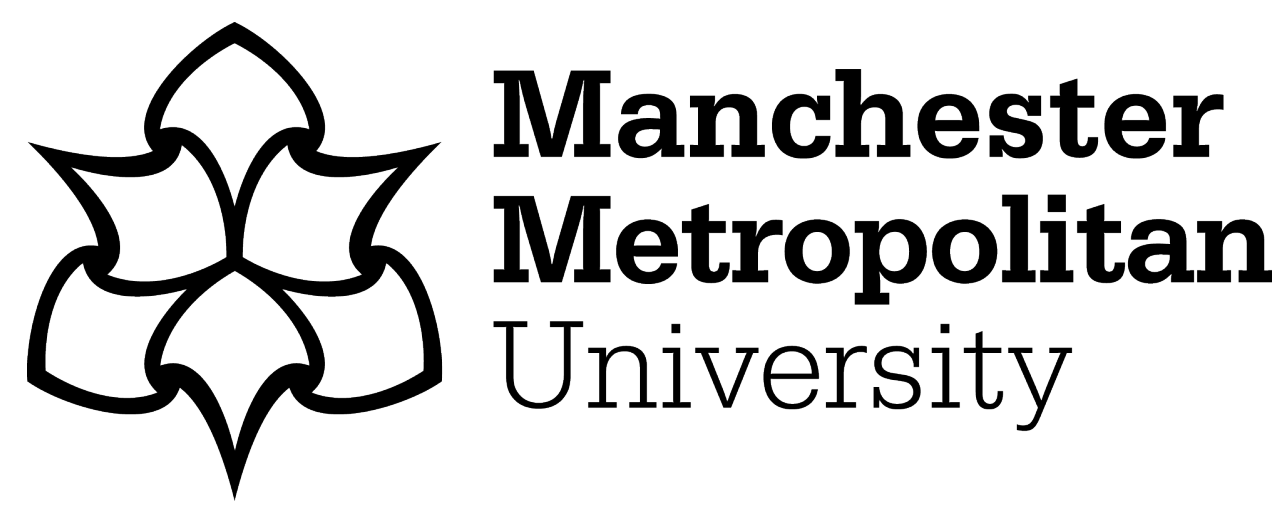

Kılıçoğlu, Gökhan, Kılıçoğlu, Derya Yılmaz and Hammersley-Fletcher, Linda (2020) Leading Turkish schools: a study of the causes and consequences of organisational hypocrisy. Educational Management Administration \& Leadership, 48 (4). pp. 745-761. ISSN 1741-1432

Downloaded from: https://e-space.mmu.ac.uk/622260/

Version: Accepted Version

Publisher: SAGE Publications

DOI: https://doi.org/10.1177/1741143218822778

Please cite the published version 


\title{
Leading Turkish schools: A study of the causes and consequences of organisational hypocrisy
}

\author{
Gökhan Kılıçoğlu (1), Derya Yılmaz Kılıçoğlu \\ and Linda Hammersley-Fletcher
}

\begin{abstract}
Schools in Turkey are primarily influenced by the Ministry of National Education (Milli Egitim Bakanlığı) through laws and regulations. Compliance with regulations might be characterised as superficial in many respects and can lead to schools 'decoupling' their espoused structures from the realities of practice. In other words, they might have policies to indicate compliance whilst at the same time practising in ways that are not coherent with these stated aims and 'ideals'. Consequently, there can be incongruence between the apparent conformity and the reality of daily activities referred to by Brunsson as 'organizational hypocrisy'. There are serious dangers with not recognising issues around proclaimed values and accepted expectations which may have pathological consequences for organisations. This article draws on semi-structured interviews with 21 staff including principals, vice principals and teachers from nine schools in the Eskişehir Provincial Directorate of National Education in Turkey to investigate the conditions under which hypocrisy is more likely to happen and what the consequences of it may be. We provide school staff with important insights on how to decrease hypocrisy in their schools and increase the authenticity of school approaches in a complex, educational environment.
\end{abstract}

\section{Keywords}

Organisational hypocrisy, school leadership hypocrisy, school inconsistency, ethics in educational organisations, organisational behaviour

\section{Context}

All aspects of life are subject to rapid development, for example the scientific, technological, political and sociological (Self and Schraeder, 2009; Senior and Fleming, 2006). Such changes have a profound influence on organisational structures and performance which in turn requires organisations to adapt and develop their organisational practices if they want to survive in a market-led environment (Morrison, 2017). Moreover, they need to respond to the demands of

Corresponding author:

Gökhan Kllı̧̧oğlu, Eskişehir Osmangazi Universitesi, Faculty of Education, Meşelik Campus, 26480, Eskişehir Turkey.

Email: gkilicoglu@outlook.com 
divergent interest groups (Milne and Patten, 2002) and seek to establish congruence between social values related to their activities and the norms of acceptable behaviour (Dowling and Pfeffer, 1975). The adoption of the practices of successful organisations is known as isomorphism (Newman, 2001). Therefore, isomorphism characterises the actions of organisations as they adapt to their environment in order to incorporate conventions about how best to do things and which goals are worth pursuing. They adopt these practices in order to gain societal approval and legitimacy.

Schools like any other organisation are subject to pressures to adapt and change in order to preserve and justify their legitimacy (March and Olsen, 1989). Schools in Turkey are primarily influenced by the Ministry of National Education (Milli Eğitim Bakanlığ1) through laws and regulations leading them to implement initiatives such as standardisation, total quality management processes and strategic planning (K1lıçoğlu et al., 2017). They also attempt to comply with the structures and practices of those organisations deemed successful. In the case of schools this compliance might be characterised as superficial in many respects and can lead to schools 'decoupling' their espoused structures from the realities of practice (Boxenbaum and Jonsson, 2008; DiMaggio and Powell, 1983). In other words, they claim to be compliant with perceived desirable structures and practices and might have policies to indicate this compliance whilst at the same time practising in ways that are not coherent with their stated aims and 'ideals'. Consequently, there can be incongruence between the apparent conformity to accepted best practices and the reality of daily activities (Boiral, 2007).

Gaps between espoused policy, what is regarded as desirable practice and what actually takes place in practice can be characterised as what Brunsson (1989) describes as 'organizational hypocrisy'. This encapsulates a position where educational organisations may experience discrepancies and contradictions between their real actions and their espoused compliance with ideologies and administrative structures. Studies examining how educational policies and practices are decoupled from one another (Falk and Blaylock, 2012; Mundy and Menashy, 2014), and how discrepancies between discourse and practice occur in civic education (Kılıçoğlu 2017a; Mundy and Menashy, 2014; Philippe and Koehler, 2005; Rus, 2008) provide an empirical background for organisational hypocrisy in schools. This article investigates the conditions under which hypocrisy is more likely to happen and what the consequences of it may be.

\section{Organisational hypocrisy}

Hypocrisy is defined as the failure to practise what one preaches, with consequent behavioural inconsistency (Hale and Pillow, 2015). Hypocrisy also implies consciousness of the gap between proclaimed values and accepted expectations (Philippe and Koehler, 2005). Thus, someone can be described as a hypocrite, where for example, they proclaim high standards and present themselves as holding positive values and virtues such as commitment, idealism and selflessness whilst practising very different characteristics (Fernando and Gross, 2006). Hypocrisy can be evidenced in behavioural inconsistencies and insincerity. Additionally, several factors regarding individual characteristics such as an intent to deceive others, weakness of will and the intent to deceive one's self may affect the presence of inconsistencies in attitudes and behaviours (Alicke et al., 2013). Further, it is argued that deliberately deceiving others, not abiding by commitments, and acting inconsistently with individuals' own values lead to hypocritical situations in organisations.

'Organisational hypocrisy' expresses the political and practical paradoxical relationships found in organisations where a loose relation or inconsistency between the real practices of organisations and their legal declarations, thoughts, promises and discourses are found. Further, organisations 
may make hypocrisy an inevitable part of working life through formulating institutional rules and norms that are not then realised in practice or perhaps not even practicable (Huzzard and Ostergren, 2002). This is partly caused through trying to satisfy the intensified demands, conflicting ideals and pressure from the political and social environment, which extends the gap between organisational realities and idealised corporate self-description (Christensen et al., 2011). Furthermore, where there is no sincerity, honesty, fairness and integrity in an organisation, inconsistency is likely to be apparent (Naus et al., 2007).

Organisational hypocrisy consists of characteristics such as contradictions in messages to staff, contradictory decisions and actions, confusion in reflecting the norms and values of the wider environment, and a failure to fulfil the organisation's stated goals and mission. Thus, it can be stated that organisational hypocrisy occurs when there are inconsistencies or disjunctures demonstrated through: (a) informal agreements or discussions; (b) formal decisions or policies recorded within the organisational hierarchy and generally enacted through written documents, including plans and budgets; and (c) the actual actions of organisational actors, as opposed to what they have formally or informally agreed upon (Fassin and Buelens, 2011).

In Turkey, schools as educational organisations, are expected to adapt their regulations, administrative and educational processes according to directives and guidelines set by the Ministry of National Education. There is a high, power distance in organisations (Hofstede, 2001) which is dominated by a bureaucratic hierarchy and obedience. Bureaucratic barriers in the Turkish education system are considered to be one of the most urgent educational problems (Erdem et al., 2011). Whilst practices may be implemented to display a legal and rational alignment with the corporate environment, the adoption of such practices may at best be superficial and lack any deep or real change to current practices (Egitimde Reform Girisimi, 2017; Kılıçoğlu, 2017b). Gumus and Akcaoglu (2013), whilst talking about primary education in Turkey, give some potential reasons for this tendency. They discuss the lack of professional development for those leading schools, how centralisation has led to high levels of bureaucratic demand on principals and question the system by which principals are selected. Thus, the focus for Turkish principals is on meeting Ministry agendas, rather than on issues around instructional leadership where they support staff development (Gumus and Akcaoglu, 2013). It is as a consequence of these varied pressures that schools may demonstrate organisational hypocrisy.

One way to approach an understanding of this divide may be to consider the work of Sergiovanni (2000) who expresses a contrast between two competing forces in schools. Specifically, the systemworld comprises policies, rules and laws for regulating structure and rationality of the education system while the lifeworld involves school culture with the needs, values, desires, beliefs and purposes which give meaning to education itself. The systemworld may dictate a set of values that put the system above the needs of students, teachers and parents. Where the system consists of rigid goals and harsh sanctions, those working within the school may find it difficult to pursue their own goals and passions, the very things that for them, make the school a worthwhile working environment. Thus, the lifeworld has trouble surviving if the systemworld is not developed in a manner sympathetic to the values of the lifeworld. A clash between lifeworld and the systemworld may lead to contradictory actions and statements in educational organisations.

Understanding the systemworld and lifeworld demonstrates why ethical dilemmas are perceived differently by different actors, so the dilemmas faced by staff are different from those experienced by principals, which in turn differ from those experienced by politicians (Norberg and Johansson, 2007). Norberg and Johansson go on to explain that strong, values-orientated professions can also be in tension with personal values. This complexity of contrasting and conflicting 
values can lead to different understandings and decisions that place others in impossible situations. Hammersley-Fletcher (2015) illustrates this through the struggle that headteachers of schools in England face when juggling between their personal educational values and those dictated by the state. This she argues, places educational leaders in a dilemma as they need to meet government requirements but this can at times conflict with deeply-held beliefs about what, in their opinion, should comprise a 'good education'. If one adds further complexity (such as autonomy) in relation to the funding and resources available to Turkish schools then these dilemmas increase.

\section{The consequences of organisational hypocrisy}

Organisational hypocrisy influences the extent to which individuals trust others within the organisation, the extent to which they become cynical about their organisation, their job satisfaction, motivation and commitment, performance and levels of absenteeism, and it impacts on job security and attitudes towards the organisation (Greenbaum et al., 2012; Han and Koo, 2010; Kowal and Roztocki, 2015; Kuchinke et al., 2008). Consequently, there are serious dangers with not recognising issues around proclaimed values and accepted expectations, which may have pathological consequences for organisations (Han and Koo, 2010; Lipson, 2006). Inconsistent acts by school principals, leaders, or teachers and broken promises may elevate negative feelings towards the school and reduce staff motivation (Yidong and Xinxin, 2013). Specifically, inconsistencies in talk, decisions and actions raise questions about the honesty and sincerity of school leaders with a subsequent loss of trust in the school (K1lıçoğlu et al., 2017; Simons, 2002). Therefore, if an organisation operates with a sustained incongruence between talk and actions, the credibility of its disclosures may be eroded (Cho et al., 2015; Deegan, 2002).

One way to address incongruence is to involve a range of staff in school decision-making. This point is important to consider in the highly-hierarchical system of Turkish schools. Solo, heroic and charismatic leadership have been found to be ineffective in bringing about sustained change (Torrance and Humes, 2014). Moreover, because the responsibilities of school leaders are increasing in terms of quantity and complexity (Barth, 2001; Copland, 2001; Elmore, 2000; Lambert, 2003 ) 'the task of transforming schools is too complex for one person to accomplish single handedly' (Lashway, 2003: 1). As Hargreaves et al. point out, school leaders in Organisation for Economic Co-operation and Development countries are also facing rising expectations 'for schools and schooling in a century characterized by rapid and constant technological innovation, massive migration and mobility, and increasing economic globalization' (Hargreaves et al., 2007: 3). Further, Crawford (2012) argues that those leaders who try to transform the social practices of schools alone, have failed to do so. Thus, there is evidence that schools would be wise to engage in sharing leadership activities.

The discussion above demonstrates some of the negative effects of organisational hypocrisy and argues that staff are potentially less likely to perform well in such circumstances. Studies of schools in such situations are limited. Thus, this article adds further to the knowledge base regarding organisational hypocrisy for revealing under what conditions hypocrisy is more likely to happen and what the consequences of it are. The aim is to assist school principals and teachers to better understand themselves and to analyse their use of rhetoric, promises and decisions, whether words are truly converted into practice, or whether their schools are merely operating in ways that only superficially meet demands. In the article, the authors provide school staff with important insights on how to decrease hypocrisy in their schools and increase the authenticity of school approaches to a complex educational environment. 


\section{Approach}

Using a qualitative approach to data gathering, the premises and consequences of organisational hypocrisy in educational settings are considered in this study. Thus, semi-structured interviews were carried out with 21 educators across nine different schools in the Eskisehir district of Turkey. The interviews included questions about participants' work and experience; their perceptions of organisational hypocrisy; and the potential consequences of organisational hypocrisy. The nine schools from the Eskişehir Provincial Directorate of National Education, which were involved in this study, varied in academic achievement and in socio-economic backgrounds. The sample included three lower-secondary schools (pupil age range 10-13 years) and six upper-secondary (high) schools (pupil age range 14-17 years), four of which were Anatolian upper-secondary (high) schools (offering a full range of opportunities), one a vocational high school (focussing on vocational training) and one a specialist social science high school. One of the Anatolian schools was designated a project school which gave it greater autonomy than the other schools in relation to budgets and selecting teachers. This was one of three Anatolian schools in the district designated as project schools. In relation to academic achievement, three upper-secondary (high) schools and one lower-secondary school were very successful with national achievements in the Transition to High Schools Exams, one lower-secondary school and one upper-secondary (high) school had poor results in Transition to Higher Education Exams (one with high levels of refugee children and the other having discipline problems), and one lower-secondary school and two upper-secondary (high) schools had average levels in the Transition to Higher Education Exams.

To ensure maximum variation, the participants comprised nine school principals, four vice school principals and eight teachers. The participants comprised 14 men and seven women, aged between 30 and 65 . Respondent verification and triangulation of participants (principal, vice principal and teacher) were employed to enhance validity (Shenton, 2004). Data were read, coded and re-coded to derive themes (Creswell, 2013). Coding and emergent themes were discussed on a regular basis and inter-code reliability was performed to gain a shared interpretation. Schools are not identified to prevent individual participants becoming identifiable. Table 1 illustrates those teachers included in this paper by pseudonym, their role within school, age range, length of service in the school, and school type.

Ethical consent and legal permissions for this study were given by the ethics committee of the university and Eskişehir Provincial Directorate of National Education. At the beginning of each interview, informed consent was obtained from all participants (Creswell, 2013). Interviews took place in the 2017-2018 academic year and were voice recorded in Turkish and transcribed verbatim and then translated into English. Each interview was conducted in the school principals' office and lasted between 33 and 54 minutes. Participants were informed about their rights to confidentiality and their ability to withdraw at any point, without prejudice.

\section{Findings}

\section{Causes of organisational hypocrisy}

In many ways the principal as the school leader can be subjected to close scrutiny as the person who is expected to take responsibility for the activities and policies of the school. However, the principal is also constrained or empowered by the policy guidance offered by the Ministry and the ways in which principals and their schools are held accountable. This led on to studying school operational level effects on leadership behaviours and practices in schools. We now look at these 
Table 1. Participants of the study.

\begin{tabular}{|c|c|c|c|c|}
\hline Participant role & Participant name & Age (years) & $\begin{array}{l}\text { Service in } \\
\text { the school (years) }\end{array}$ & School type \\
\hline Principal & Ali & $50 \mathrm{p}$ & $15-20$ & Lower-secondary school* \\
\hline Principal & Okan & $50 \mathrm{p}$ & $5-10$ & Lower-secondary school* \\
\hline Principal & Osman & $40-50$ & $5-10$ & Upper-secondary (high) school** \\
\hline Principal & Haydar & $40-50$ & $0-5$ & Upper-secondary (high) school** \\
\hline Principal & Halim & $40-50$ & $0-5$ & Upper-secondary (high) school** \\
\hline Principal & Bayram & $40-50$ & $0-5$ & Lower-secondary school* \\
\hline Principal & Deniz & $40-50$ & $0-5$ & Lower-secondary school* \\
\hline Principal & Ibrahim & $40-50$ & $0-5$ & Upper-secondary (high) school** \\
\hline Vice Principal & Kenan & $30-40$ & $0-5$ & Lower-secondary school* \\
\hline Vice Principal & Salih & $40-50$ & $0-5$ & Upper-secondary (high) school** \\
\hline Vice Principal & Sibel & $40-50$ & $0-5$ & Lower-secondary school* \\
\hline Vice Principal & Selim & $30-40$ & $0-5$ & Upper-secondary (high) school** \\
\hline Teacher & Ayse & $40-50$ & $0-5$ & Lower-secondary school* \\
\hline Teacher & Fatma & $30-40$ & $0-5$ & Lower-secondary school* \\
\hline Teacher & Mert & $40-50$ & $0-5$ & Lower-secondary school* \\
\hline Teacher & Muhittin & $40-50$ & $0-5$ & Upper-secondary (high) school** \\
\hline Teacher & Ismail & $40-50$ & $5-10$ & Upper-secondary (high) school** \\
\hline Teacher & Yasemin & $30-40$ & $0-5$ & Upper-secondary (high) school** \\
\hline
\end{tabular}

Note: * pupil age range $10-13$ years; and ${ }^{* *}$ pupil age range $14-17$ years.

contexts through the data gathered in order to understand the causes of organisational hypocrisy in more detail.

The role of principal in relation to hypocrisy. Participants associated particular leadership traits as important in avoiding organisational hypocrisy. These characteristics were broadly linked to personal integrity such as acting on commitments, being trustworthy and honest, making moral and values-led decisions, demonstrating empathy and respect for others, showing courage and commitment to the profession and being responsible. Principals added some further qualities associated with paying attention to one's own appearance and behaviour in addition to demonstrating long-term commitment. Principals voiced high expectations for themselves as the following quotation demonstrates.

Ali: First, the school principal should be impartial... He should act equally and fairly. I mean, he should do his job as it should be, as a role model at school. Everyone should look at the principal and compare themselves with his image. They would not trust you, because they say that the fish rots from the head down, if you do not do it the rank and file might not do it as well... The school is as much a school as its principal. According to this, first of all, the principal should get his act together.

This statement is illustrative of the power of hierarchy in the Turkish school system where the principal holds an important position and is expected to act as an exemplar of good professional behaviour to which others can aspire. It is a role imbued with high expectations of the principals' leadership, which may or may not be realistic. It also relies on the principal being able to see 
themselves as others do. This level of power may be open to abuse as the following teacher reflecting on the role of principal illustrates.

Ayse: I think there are problems about his/her personality. Machiavellian personality trait... I also think that high ego is another reason. I would say something today, and tomorrow I would do what I want. I am the principal, I am your leader. It could be due to the fact that he/she may consider himself/ herself above the rest since he/she has the title. Principals should not make promises they cannot keep. They should do the things they ask of us. They must be hardworking, responsible, orderly and disciplined, consistent, honest, and trustworthy.

In such circumstances where principals did abuse power, teachers argued that they were viewed as bullies and as hypocrites. They also indicated disillusionment when principals did not live up to expectations. Thus, there is a tension in play here between expectations and ego. Another teacher outlines the challenges and emphasises the need for a principal to exercise values-led leadership.

Fatma: The school principal ... will have no trouble if you avoid [engaging in] all kinds of meddling. However, this would lead the school to nowhere. You must be honest; the leader must know what he wants. He should not move with the wind to prevent organisational hypocrisy. Of course, you should be an ethical leader ... In other words, you should defend your moral values, institutional values ... If you made a decision, you should enforce it. You shall not lie.

This statement further illustrates not only the pressure on principals to act with integrity but also the pitfalls should he or she fail in this endeavour. There appears to be a strict yet unspoken set of rules operating here which is unforgiving should the principal fail to meet these high standards. Moreover, there was no discussion about how as a leader, the principal might share concerns and policy issues with staff. Thus, the role seemed to be that of acting as a 'super-being' leaving no space for making mistakes and learning from these mistakes. This in itself could lead to some level of apparent hypocrisy.

The role of accountability within hypocrisy. During the interviews it became apparent that many participants felt that school strategy was a paper exercise divorced from the reality of school life. They argued that because no one was held accountable then there was no stability in institutional activity.

Mert: I think the strategic planning is only on paper... So, when the external inspectors come, for example, when someone from the Ministry come, where is your planning, where are your papers? That's it. What has been done? In fact, they have to check this out, but I do not think that they do such work. For example, meetings are held in the beginning of the year, everybody has a task. Here is your duty, there is yours. Everyone is assigned duties, because they have to be assigned ... . I cannot say I did anything...

This teacher argued therefore that the tasks assigned to staff were on paper only and that there were no repercussions for not acting as expected; the Ministry was focussed on the paperwork alone. A principal reinforced this claim, 
Okan: Now they say to you from the top that you should do this, implement that, but they do not follow up. You do it once, twice, then you do it on paper and leave it there ... and since there is no follow-up, you start going slowly backwards after three years.

Another principal, Osman, asserted the same, pointing to the feeling of hypocrisy built into the schooling system from the Ministry down. Furthermore, participants stressed the fact that curriculum and completion of the curriculum content, the annual school plans, and group meetings in provincial, district and school level were ceremonial proceedings only. Test-based acceptance of the students in higher education and secondary education institutions, it was argued, varied wildly. Moreover, participants stated that they had no autonomy in the design and control of instructional processes. Ibrahim illustrated this by arguing that 12 th grade students who take Transition to Higher Education Exams may elect their own topic. Staff then have to devise a way for the student to fulfil the needs of this topic whilst facing contradictions between curriculum, distributed textbooks and exam questions. Muhittin explains that the curriculum provided is bulky and outdated.

Muhittin: ... everybody downloads the annual plans from the internet, you know. You do not have a lot of freedom anyway, actually! There is a curriculum that has its goals and demands, you plan based on that. It does not provide a lot of freedom...

A vice-principal expresses frustration about teachers' lack of control over the curriculum and the ridiculous nature of meeting and agreeing a curriculum that no-one will implement.

Kenan: We conduct regional groups, provincial groups. We write down the same stuff every year. We make recommendations to the Directorate of National Education, the Ministry, etc. I do not remember getting any feedback from any of these in twenty years... This is in fact only rhetoric, is it not? We shall do this, we shall do that, but none is implemented.

What our participants' comments highlight is the gaps between policy-making and practice which clearly illustrate hypocrisy and the unwillingness of policy-makers to engage with teachers in designing more workable solutions that can then be monitored to ensure that changes are being adopted.

Principals also pointed to the rapid changes in educational policies and a lack of consistency between them, which made them even more difficult to implement.

Haydar: There is an approach in our society. Everything should be complete on paper; the rest is not important; 'the blind are leading the blind'.

Sibel argued that such paper-only compliance inevitably led to behavioural hypocrisy. Thus, it could be argued that in this study the hypocrisy in school leadership was underpinned by the hypocrisy of educational policy-making activity. Principals may as a result be finding it difficult to work with integrity.

Halim: Most things are not up to you. So, a change ordered by the top administration, a change in the policy, negates everything at the school in a day. In a single day, in one day, I was working in primary education. The following day the school became a secondary school. So, all your goals, the things you ought to do were cancelled ... people develop such a distrust. 
Kenan: people are not aware what we experience in the field. In their perspective, in their offices, most of them determine the rules and the legislation. They do not question whether it is practical or not.

It was clear from these interviews that teachers and principals were placed in an invidious position where they were inevitably going to experience hypocrisy. The principals were expressing the regulating authority's lack of understanding of the realities of school life. This led to tensions between educational policies and promises, which in turn led school staff to feeling that the leadership of schools was full of hypocrisy and becoming disillusioned.

School operational factors. One principal talked about the importance of sharing leadership power.

Haydar: The school principal must initially have organisational skills and competence. Why? Because ... other leaders are required to emerge ... For example, instead of monitoring whether all teachers achieved the course or school objectives from above, I have to distribute these tasks ... a leadership should emerge among the group heads. The group leader should have such a power and authority and supervise whether the teachers fulfil their goals.

The interesting point made within this quotation is that despite notions of sharing power the message is about ensuring staff do what is expected of them. Thus, this is not about sharing emancipator power but rather about sharing mechanisms of control with 'group heads' who ensure that teachers are supervised.

Some principals attributed gaps between promises and actions to situations where budgets were problematic. Therefore, school aspirations and policy demands could not be met.

Bayram: I promised my teachers and students. I said that we will have a graduation program, we even took a decision for that in the board of teachers, but I could not fulfil this promise because the institutions that promised support were not willing to provide funding... We had a team called school development management team. It is not working... Even the toilets have problems. This is a very troubled school... It is forbidden to accept donations and we need a budget in the strategic plan... accountability requires the availability of the necessary support that the school needs...

Clearly this principal was facing what he saw as insurmountable problems with meeting educational policy demands because poor budget conditions meant that basic needs were not being met. This had repercussions for all aspects of school life and the principal felt he was letting down staff and pupils. Another principal explained that one had to be very careful about the promises made in that role of responsibility. Okan argued that staff had requested new chairs for the teachers' room which he had agreed, only to find that the budget did not allow for this and that the staff had felt long term resentment about this.

Whilst working in a system where inspections of education are restricted to the paper work, principals nevertheless are responsible for teacher compliance. This leads to behaviours that expose teachers to open scrutiny within the school. As one teacher in our study explained,

Ayse: Those who do not comply are announced. They are warned, either by calling them in or they are declared for everyone to see. Then they have to comply. 
This form of public humiliation would be an anathema in many countries and certainly regarded as counter-productive. Nevertheless, there was recognition that teachers needed to be accountable for their work.

Fatma: There is a serious lack of order, lack of inspection. Now I support private schools a lot in this sense. The quality of teachers' work should be supervised.

A principal also wanted to see greater control,

Halim: Control is the responsibility of the principal. This authority should be utilised instead of leaving it to only the teachers' self-control.

So, we have a dual message that, in some cases, teachers may be singled out and humiliated for non-compliance and also that greater controls over teacher quality are necessary. Halim indicates that it is not sufficient to trust teachers to do a good job. These are staff who are seeing accountability as a means to rationalise and gain control of a chaotic education system. The apparent fluctuations in practices between schools and principals and the lack of oversight and disorder within the school system itself were clearly unsettling staff. As a consequence, a struggle to deal with apparent multiple aspects of organisational hypocrisy was arising.

The quality and skill of individual teachers was discussed in relation to school success. As Ismail argued, 'In general the teacher's experience, knowledge, and equipment are the factors that lead to success'. There was however, a belief that region, facilities, parents and the local environment also influenced school success.

Yasemin: The potential of the school is not only the potential of the students, but also the teacher profile, the parent profile, and the social environment should be taken into account. Where do we live?

The goal of every region is different.

Osman suggested that it would be sensible to set realistic goals for the school and to develop an institutional structure that could outlast the leadership of it, 'Institutional culture should develop; the individuals should come and go, but the school practice should remain the same'. Here is an argument for structures and practices that can outlast the staff within the schools. This of course could be a mixed blessing. Despite hearing the plea for continuity, if structures become too rigid this can be a hindrance to innovative practice. What was apparent across the range of schools and interviews was the need for a transparent system within which staff could feel secure.

\section{Consequences of organisational hypocrisy}

When considering the data about the consequences of organisational hypocrisy, two sub-categories developed to describe this, namely the individual and organisational consequences.

Individual consequences. Participants stated that organisational hypocrisy led to negative consequences both for teachers and principals in schools. Hypocrisy was characterised as leading to problems of trust between teachers, the school administration and the principals. It was also stated that it had a negative impact on teachers' motivation, job satisfaction, commitment to the school and performance. Teachers expressed that they felt worthless, unhappy, angry, indignant and 
restless. Furthermore, organisational hypocrisy led to alienation and poor communication with the principal and teachers avoiding participating in schoolwork, wanting to leave the school and they avoided taking risks. One principal summed this up in the following way,

Deniz: The trust in the administration is reduced and completely disappears in my opinion. No-one values you; no administrative authority is left in the institution; there is no more dignity. There would be no academic achievement. The teacher would not instruct the class ... Their commitment is reduced. In fact, there would be no belongingness to the institution.

Further, a teacher explained,

Ayse: I lost confidence. Anger, a rage came onto me. I pretended to do my work. But of course, I did not feel happy when I arrived at the school. It really affected our achievement. It was not a peaceful and safe school.

Another teacher explained the process of becoming alienated.

Fatma: There is insecurity at first. Then, you say count me out of the action plan. You say, do not hope for much and if you are not very ambitious, you end up a simple civil servant. You would not take any more risks at work.

The participants stated that hypocritical principals risked their reputation and authority, their credibility could be lost, their leadership is questioned and their ability to influence teachers is damaged. Furthermore, inconsistent, administrative actions could injure the trust of students and lead to behavioural problems. Two principals shared their thoughts about what can happen where staff detect hypocrisy.

Ibrahim: When we experience inconsistencies, the staff would let go ... you cannot make a teacher do anything. The teacher would not instruct class. Your ability to make things happen is gone. That teacher would not do anything at school willingly.

Okan: It would lead to failure. It would lead to behavioural problems. It would lead to wayward teachers. If you cannot fulfil your promises and behave, the reputation of the administration will be lost.

Clearly, for the staff interviewed, organisational hypocrisy has serious implications for cooperation among staff and for their support of the school and their interest in their job, with consequent implications for the organisation functioning appropriately.

Organisational consequences. Participants emphasised potential devastating consequences for the organisation when faced with hypocrisy. These consequences included: organisational conflict; decrease in academic achievement; creation of a tense, restless and unreliable working environment; increase in organisational gossip; spread of inconsistency to all employees; chaos; emergence of new leaders and cliques in school; and the development of unhealthy school cultures. One principal characterised the following consequences particularly for the image and therefore the attractiveness of the school to parents,

Bayram: It would affect occupational health. The concept we call labour peace would disappear. In turn, the school will receive negative promotion because these issues would be discussed out of the 
school as well ... There would be disconnection between the school principal and teachers, there would a serious problem like they constantly fight each other. It would seriously contribute to the damage of the image.

Another principal emphasised consequent issues around insecurity.

Halim: Insecurity is a big chaos in this kind of thing, in participation in future decisions, trust in the leader, etc. You will never do what you would do again as much as you want. You cannot convince people, you cannot be convincing. In brief, your leadership is questioned.

A third principal talked about the effects of hypocrisy on culture.

Selim: It would destroy the organisational culture, it would injure it very badly. Then, it demonstrates that you could not implement the decisions you take... and, in time, your administrative qualities are questioned. If you say, 'I can do it', you would add one mistake on top of another. After a while, you would be unable to implement anything because you are left alone... If the leader is left alone, the leader does not bear a chance of staying as a leader anyway.

Vice-principal Salih argued that all staff through to the school caretakers are affected by hypocrisy and that it slowly destroys the whole school. The negative impacts of organisational hypocrisy were clearly evident to all our participants. Moreover, they were all experiencing elements of hypocrisy.

\section{Discussion}

This study offers a view from school staff in the Eskişehir Provincial Directorate of National Education in Turkey that helps inform thoughts about the hypocrisy that can arise from inconsistent and autocratic power relations, particularly where the systemworld of Sergiovanni (2000) is given preference over the lifeworld. Whilst the sample of teachers interviewed is limited we are nonetheless presented with a sense of the problematic nature of educational policy-making where only the paperwork is inspected, a system where principals are focussed on conformity rather than instructional leadership (Gumus and Akcaoglu, 2013), and where leadership appears as inconsistent (Yidong and Xinxin, 2013). In this study teachers were looking for leaders that were values-led in a way that addresses the gaps between conformity and practice (Boiral, 2007). In addition, principals were demonstrating frustration with staff who did not conform to instruction. This poses some challenging questions for the field of educational leadership around understandings and acceptances of notions of autonomy and accountability.

What is important about this study is the extent to which teachers at all levels of school organisation report experiences with organisational hypocrisy. Moreover, it is clear that this is a situation which breeds insecurity, a deep frustration and resentment, together with a distraction from the purposes of education. Whilst limited in scope this study potentially raises important questions about the values underpinning education in schools and the varied understandings of this from the Ministry through to teachers in Turkish schools. Policy-makers need to be aware of what is and is not reasonable to ask of schools in terms of educational practices. Setting impossible goals with heavy penalties for a lack of conformity simply forces schools to perform a superficial role of compliance. It also places principals in a difficult position where they do not always have the 
resources to accomplish what is being asked of them. In addition, there needs to be a greater understanding about what can be expected of principals. Whilst they are expected to be 'paragons of virtue', then they are unlikely to admit to errors of judgement or call upon other perspectives through consulting colleagues when making decisions. As argued by Begley (2006), authentic leadership is grounded in the understanding or interpretation of observed or experienced valuation processes as well as in ethical decision-making processes. The role as outlined by the principals and teachers seems to be one full of ideals where the individuals filling these positions act without staff having the ability to hold them to account.

Dejours and Deranty (2010) argue, in order for any workers to achieve work-based goals, that they must be allowed freedoms to innovate and discover their own solutions to make this happen. Dictating not only the goals but the approach taken to achieve them is doomed to failure as nothing happens in exactly the same way as envisaged. Thus, people need the flexibility to improvise. It was clear from some of the responses that this is what teachers are doing, but at the same time they were aware that this was not acceptable to policy-makers. Further, without any monitoring of the educational experiences of pupils it is difficult to ensure what kinds of educational experience they are getting. This leads people such as Greany (2018) to argue that accountability is important. Whilst some European nations argue that their systems of accountability have gone too far and are now inhibiting freedoms, Turkey has been operating with so few checks that chaos seems part of educational provision. This leaves us with a dilemma around accountability and the extent to which it is useful and necessary.

As school autonomy grows so does the freedom of school leaders to influence policies and structures (Dou et al., 2016). In order to ensure that principals are not acting on the basis of their own ego or bullying staff then there is, however, a need for some accountability which Briggs and Wohlsetter (2003) argued improves student achievement and parental involvement. It may be important to remind Turkish schools, as they develop their educational practices, of the problems with too much accountability. As Glatter (2012: 570) argued in relation to education demands in England

Schools have acquired far more responsibilities and the centre has been transformed from a trusting referee and resource provider to a demanding and impatient managing director with frequently changing identity and priorities.

Clearly, this appears to be the very situation that Turkey is attempting to address albeit arising from very different circumstances. Perhaps the solution lies in the interpretations of 'autonomy' and 'accountability' which as Glatter argued have very different connotations in circumstances where schools have had relative freedoms to those where schools have experienced little ability to manoeuvre. These are, therefore, important concepts to explore whilst instigating structural reform that adds security, autonomy and some accountability to the education system.

\section{Declaration of conflicting interests}

The author(s) declared no potential conflicts of interest with respect to the research, authorship, and/or publication of this article.

\section{Funding}

This research was supported by Eskişehir Osmangazi University Scientific Research Projects [Project Number 2017/21032]. 


\section{ORCID iD}

Gökhan K1liçoğlu (D) https://orcid.org/0000-0002-6322-228X

\section{References}

Alicke M, Gordon E and Rose D (2013) Hypocrisy: What counts? Philosophical Psychology 26(5): 673-701.

Barth RS (2001) Teacher leader. Phi Delta Kappan 82(6): 443-449.

Begley AM (2006) Facilitating the development of moral insight in practice: Teaching ethics and teaching virtue. Nursing Philosophy 7(4): 257-265.

Boiral O (2007) Corporate greening through ISO 14001: A rational myth? Organization Science 18(1): $127-146$.

Boxenbaum E and Jonsson S (2008) Isomorphism, diffusion and decoupling. In: Greenwood R, Oliver C, Sahlin K and Suddaby R (eds) The SAGE Handbook of Organizational Institutionalism. London: SAGE, pp.78-98.

Briggs KL and Wohlstetter P (2003) Key elements of a successful school-based management strategy. School Effectiveness and School Improvement 14(3): 351-372.

Brunsson N (1989) The Organization of Hypocrisy: Talk, Decisions and Action in Organizations. New York: John Wiley and Sons, Inc.

Cho CH, Laine M, Roberts RW and Rodrigue M (2015) Organized hypocrisy, organizational façades, and sustainability reporting. Accounting, Organizations and Society 40(3): 78-94.

Christensen L, Morsing M and Thyssen O (2011) The polyphony of corporate social responsibility: Deconstructing accountability and transparency in the context of identity and hypocrisy. In: Cheney G, Steve M and Debashish M (eds) The Handbook of Communication Ethics. New York: Routledge, pp.457-474.

Copland MA (2001) The myth of the super principal. Phi Delta Kappan 82(7): 528-533.

Crawford M (2012) Solo and distributed leadership: Definitions and dilemmas. Educational Management Administration \& Leadership 40(5): 610-620.

Creswell JW (2013) Qualitative Inquiry and Research Design: Choosing Among Five Approaches. 3rd edition. Thousand Oaks: SAGE.

Deegan C (2002) Introduction: The legitimising effect of social and environmental disclosures - A theoretical foundation. Accounting, Auditing and Accountability Journal 15(3): 282-311.

Dejours C and Deranty J-P (2010) The centrality of work. Critical Horizons: A Journal of Philosophy and Social Theory 11(2): 167-180.

DiMaggio PJ and Powell WW (1983) The iron cage revisited: Institutional isomorphism and collective rationality in organizational fields. American Sociological Review 48(2): 147-160.

Dou D, Devos G and Valcke M (2016) The relationships between school autonomy gap, principal leadership, teachers' job satisfaction and organizational commitment. Educational Management Administration \& Leadership 45(6): 959-977.

Dowling J and Pfeffer J (1975) Organizational legitimacy: Social values and organizational behavior. Pacific Sociological Review 18(1): 122-136.

Elmore R (2000) Building a New Structure for School Leadership. Washington, DC: The Albert Shanker Institute. Available at: http://www.shankerinstitute.org/sites/shanker/files/building.pdf(accessed 10 November 2018).

Erdem M, Aydin I, Tasdan M and Akin U (2011) Educational problems and solutions in Turkey: The views of district governors. Educational Management Administration \& Leadership 39(2): 242-256.

Egitimde Reform Girisimi ((ERG) (2017) Egitim Izleme Raporu 2016-2017 [Education Monitoring Report 2016-2017]. Istanbul: ERG. [In Turkish.] 
Falk CF and Blaylock BK (2012) The H factor: A behavioral explanation of leadership failures in the 20072009 financial system meltdown. Journal of Leadership, Accountability, and Ethics 9(2): 68-82.

Fassin Y and Buelens M (2011) The hypocrisy-sincerity continuum in corporate communication and decision making: A model of corporate social responsibility and business ethics practices. Journal of Business Ethics 98(3): 425-453.

Fernando M and Gross M (2006) Workplace spirituality and organizational hypocrisy: The Holy Water-Gate case: Australia New Zealand Academy of Management (ANZEM), Queensland. Available at: https://ro. uow.edu.au/commpapers/159 (accessed 12 November 2018).

Greany T (2018) Innovation is possible, it's just not easy: Improvement, innovation and legitimacy in England's autonomous and accountable school system. Educational Management Administration \& Leadership 46(1): 65-85.

Greenbaum RL, Bardes Mawritz M and Piccolo RF (2012) When leaders fail to 'walk the talk': Supervisor undermining and perceptions of leader hypocrisy. Journal of Management 41(3): 929-956.

Glatter R (2012) Persistent pre-occupations: The rise and rise of school autonomy and accountability in England. Educational Management Administration \& Leadership 40(5): 559-575.

Gumus S and Akcaoglu M (2013) An analysis of teachers' perceptions and current policy. Educational Management Administration \& Leadership 41(3): 289-302.

Hale WJ and Pillow DR (2015) Asymmetries in perceptions of self and others' hypocrisy: Rethinking the meaning and perception of the construct. European Journal of Social Psychology 45(1): 88-98.

Hammersley-Fletcher L (2015) Value(s)-driven decision-making: The ethics work of English headteachers within discourses of constraint. Educational Management Administration \& Leadership 43(2): 198-213.

Han J and Koo J (2010) Institutional isomorphism and decoupling among Korean firms: Adoption of performance compensation system. Korean Journal of Sociology 44(3): 27-44.

Hargreaves A, Halász G and Pont B (2007) School leadership for systematic improvement in Finland: A case study report for the OECD activity Improving School Leadership. Available at: https://www.bestlibrary. org/files/school-leadership-for-systematic-improvement-in-finland.pdf (accessed 22 October 2018).

Hofstede G (2001) Culture's Consequences: Comparing Values, Behaviors, Institutions, and Organizations Across Nations. Thousand Oak: SAGE Publications.

Huzzard T and Ostergren K (2002) When norms collide: Learning under organizational hypocrisy. British Journal of Management 13 (Supplement 2): 47-59.

Kılıçoğlu G (2017a) Consistency or discrepancy? Rethinking schools from organizational hypocrisy to integrity. Management in Education 31(3): 118-124.

Kılıçoğlu G (2017b) Organizational hypocrisy and integrity in Turkish context: A theoretical analysis. Educational Administration: Theory and Practice 23(3): 465-504.

Kılıçoğlu G, Yılmaz Kılıçoğlu D and Karadağ E (2017) Do schools fail to 'walk their talk'? Development and validation of a scale measuring organizational hypocrisy. Leadership and Policy in Schools. Epub ahead of print 22 September 2017. DOI: 10.1080/15700763.2017.1371762.

Kowal J and Roztocki N (2015) Do organizational ethics improve IT job satisfaction in the Visegrád group countries? Insights from Poland. Journal of Global Information Technology Management 18(2): 127-145.

Kuchinke KP, Kang HS and Oh SY (2008) The influence of work values on job and career satisfaction, and organizational commitment among Korean professional level employees. Asia Pacific Education Review 9(4): 552-564.

Lambert L (2003) Leadership Capacity for Lasting School Improvement. Alexandria: Association for Supervision and Curriculum Development.

Lashway L (2003) Distributed leadership. Research Roundup 19(4): 3-5. 
Lipson M (2006) Organized hypocrisy and global governance: Implications for United Nations Reform. In: Annual convention of the International Studies Association, San Diego, USA, 22-25 March.

March JG and Olsen JP (1989) Rediscovering Institutions: The Organizational Basis of Politics. New York: The Free Press.

Milne M and Patten D (2002) Securing organisational legitimacy - An experimental decision case examining the impact of environmental disclosures. Accounting, Auditing, and Accountability Journal 15(3): $372-405$.

Morrison AR (2017) Beyond the status quo - Setting agenda for effective change: The role of leader within an international school environment. Educational Management Administration \& Leadership 46(3): $511-529$.

Mundy K and Menashy F (2014) The World Bank and private provision of schooling: A look through the lens of sociological theories of organizational hypocrisy. Comparative Education Review 58(3): 401-427.

Naus F, van Iterson A and Roe R (2007) Organizational cynicism: Extending the exit, voice, loyalty, and neglect model of employees' responses to adverse conditions in the workplace. Human Relations 60(5): 683-718.

Newman J (2001) Modernizing Governance: New Labour, Policy and Society. London: SAGE.

Norberg K and Johansson O (2007) Ethical dilemmas of Swedish school leaders: Contrasts and common themes. Educational Administration Management \& Leadership 35(2): 277-294.

Phillippe TW and Koehler JW (2005) A factor analytical study of perceived organizational hypocrisy. SAM Advanced Management Journal 70(2): 13-20.

Rus C (2008) The model of organized hypocrisy applied to Romanian civic education policies and practices. Journal of Social Science Education 9(1): 112-120.

Self DR and Schraeder M (2009) Enhancing the success of organizational change: Matching readiness strategies with sources of resistance. Leadership and Organization Development Journal 30(2): 167-182.

Senior B and Fleming J (2006) Organizational Change. Harlow: Pearson Education.

Sergiovanni TJ (2000) The Lifeworld of Leadership: Creating Culture, Community, and Personal Meaning in Our Schools. San Francisco: Jossey-Bass.

Shenton A (2004) Strategies for ensuring trustworthiness in qualitative research projects. Education for Information 22(2): 63-75.

Simons T (2002) Behavioral integrity: The perceived alignment between managers' words and deeds as a research focus. Organization Science 13(1): 18-35.

Torrance D and Humes W (2014) The shifting discourses of educational leadership: International trends and Scotland's response. Educational Management Administration \& Leadership 43(5): 792-810.

Yidong T and Xinxin L (2013) How ethical leadership influence employees' innovative work behavior: A perspective of intrinsic motivation. Journal of Business Ethics 116(2): 441-455.

\section{Author biographies}

Gökhan Kılıçoğlu is currently working as an assistant professor at Eskişehir Osmangazi University. His research interests are organisational behavior, change management, educational leadership, educational policy and sociology of education.

Derya Yılmaz Kılıçoğlu is currently working as an assistant professor at Eskişehir Osmangazi University. Her research interests are educational leadership, organisational change, organisational behavior, change management in schools and educational sociology. 
Linda Hammersley-Fletcher is a Reader in Educational Leadership and Management in the Education and Social Research Institute at Manchester Metropolitan University. Linda does research on developing teacher voice, educational policy and its relationship with educational values, educational leadership and management. 